\title{
Experimental Study on the Failure Characteristics of Strata With Different Filling Rates in Long-wall Filling Mining
}

\author{
JIA Lin-gang ${ }^{1}, 2$ \\ ( ${ }^{1}$ Mine Safety Technology Branch of China Coal Research Institute, Beijing 100013, China; ${ }^{2}$ State Key Laboratory of Coal Mining and \\ Clean Utilization（China Coal Research Institute）, Beijing 100013, China)
}

\begin{abstract}
In order to study the mechanical characteristics including deformation, displacement and stress distribution of surrounding rock during the process of filling mining with different filling rate, according to the geological and mining conditions of the 12307 working face in some coal mine, the analyses of simulation were synthetically applied. The results show that the deformation and failure of overburden rock is closely related to the filling rate, when the filling rate is low, the fractures are extensive, longitudinal and transverse fractures are staggered, the vertical displacement of rock strata is differentiated obviously,while filling rate is high, the fractures appeared only in low strata, the rock strata displacement main occurs near the immediate roof, the strata displacement curves in the stable subsidence area are almost together, the rock presents the overall bending deformation, from the roof to the surface layers are whole movement characteristics. There is a power function between the influence distance and the filling rate, the concentrated stress decreases linearly with the increase of filling rate. The filling rate is an important factor to control the strata movement and surface deformation, the results of the study are of great significance to guide practice in filling mining.
\end{abstract}

\section{Introduction}

Filling mining is a green mining process, which can replace coal resources by filling materials, control the strata movement and reduce the surface subsidence, so as to protect the ground buildings and ecological environment of the mining area ${ }^{[1-3]}$. Long-wall backfill mining basically does not change the original mining method,only add the filling system on the initial foundation, reduce the foundation construction and investment, which is an effective filling mining method. It is difficult to directly observe the stress and failure characteristic of overlying strata in the process of filling mining, and the simulation experiment of similar materials is an important means to study the deformation and failure, stress distribution, the movement of the surface and surrounding rock ${ }^{[4-5]}$. By means of the simulation test method of similar materials in the laboratory, the movement characteristics of overlying strata in filling and mining can be better analyzed in combination with engineering application.

In recent years, Chinese experts and scholars have studied the theory of backfill support roof and the mechanism of overlying strata failure, and so on. Literature [6] has established the dynamic mechanics model of long-wall working face backfill mining roof by using the difference thin plate theory, and analyzed and studied the influence of the working face length on the deformation and failure of key layers. In literature [7], based on the movement characteristics of the rock strata with long-wall filling mining, the subsidence equation of the roof in the mining field and the calculation formula of coal pillar bearing load were derived, and the criterion of coal pillar instability was proposed in combination with the theory of ultimate strength. Literature ${ }^{[8]}$ proposed the theoretical model of continuous curved beam in overburden rock strata for filling and mining, expounded the geometric and mechanical characteristics of continuous curved beam, pointed out the conditions for continuous curved beam formed by roof, and analyzed the quantitative relationship between continuous curved beam and key layer. Literature [9] aimed at the problem of rock strata movement and control in the "under three" coal mining with filling mining, the concept of "backfill + coal pillar + bearing rock" collaborative support system was proposed considering the joint coordination of backfill, coal pillar and bearing rock. In literature ${ }^{[10]}$, the flexural equation of roof rock under the coupling of backfill and coal pillar was derived. Literature ${ }^{[11]}$ studied the overburden rock structure model and its movement rule of the paste filling in the coal pillar belt. Literature ${ }^{[12]}$ combined similarity simulation and numerical simulation to study the process of working face mining and coal gangue filling. 
The results which studied from different angles the mechanics characteristics of rock movement control principle, promote the development and application of paste filling mining, however, to the problem in filling rate is less research, the filling rate is an important factor of filling mining technique, not only involves filling material savings and cost,but with strata and surface movement and deformation are closely related. Therefore, it is of great theoretical and engineering significance to study and analyze the filling rate to overburden movement.

\section{Engineering background}

Some coal 2307 working face is located in the southwest of the mine, the main mining no. 3 coal seam is in Jurassic system in Jurassic yan'an group,its average depth is $160 \mathrm{~m}$, thickness is $3.7 \mathrm{~m}$. The roof strata are made of sandstone, silt stone and mud stone, argillaceous sandstone, the direct roof thickness is about $3 \mathrm{~m}$, the dip angle of the coal seam is $1^{\circ}$, the regional geological structure is simple, the ground is aeolian sand, belong to half desert hills landform, form fragile ecosystem. In order to control the surface subsidence and keep the aquifer from being damaged, the comprehensive mechanized long-wall paste filling and mining technology was adopted. The working face was $1150 \mathrm{~m}$ long and $160 \mathrm{~m}$ wide. The filling material is paste made of wind-blown sand, fly ash, cement and auxiliary materials, which is made into paste slurry on the ground and sent to underground goaf by pipeline pump.

\section{Physical similar simulation scheme}

\subsection{Principle of similarity simulation experiment}

The essence of similarity simulation is to make a model of materials with similar mechanical properties to the prototype and then carry out engineering excavation to observe and study the deformation and failure of surrounding rocks. According to the three similarity experimental theorems of geometric similarity, kinematic similarity and dynamic similarity, combined with the experimental purpose and geological mining conditions, the geometric similarity ratio is $C_{L}=100$, and the bulk density similarity ratio is $\mathrm{C}=1.6$. Due to the similarity theory, it is concluded that the stress-similarity ratio is $\mathrm{C}_{\sigma}$ $=\mathrm{C}_{\mathrm{L}} \mathrm{C}_{\gamma}=160$, and the time similarity ratio is $\mathrm{Ct}=10$, On the basis of geometric similarity ratio, the size of the experimental model whose length $\times$ width $\times$ height is $3 \mathrm{~m}$ $\times 0.3 \mathrm{~m} \times 1.7 \mathrm{~m}$; the actual size of the simulated working face length $\times$ width $\times$ height is $300 \mathrm{~m} \times 30 \mathrm{~m} \times 170 \mathrm{~m}$. The coal seam thickness is $3.7 \mathrm{~m}$, its depth is $160 \mathrm{~m}$, bottom plate thickness is $7.5 \mathrm{~m}$, mining advance length is $280 \mathrm{~m}$.

\subsection{Displacement and stress measuring arrangement}

Displacement measurement points: twelve lines of displacement measuring were set in the model during the process of model laid,one line is located in the bottom, others are arrangement between the roof and the surface, roof line is away from coal seam $5 \mathrm{~cm}$, near the roof the distance of measuring-point arrangement is increased, its spacing is $10 \mathrm{~cm} \times 15 \mathrm{~cm}$, the longitudinal spacing of the above measuring lines is $10 \mathrm{~cm}, 15 \mathrm{~cm}$ and $17.5 \mathrm{~cm}$, and the horizontal spacing of the measuring points in the same layer is $15 \mathrm{~cm}$, and a total of 240 displacement measurement points are arranged, which to observe displacement of rock strata in the process of mining and filling. Then the movement and deformation law of overburden and surface are analyzed.

Stress measurement point: Bx120-50AA resistive strain gauge was used to observe the stress change of coal seam and surrounding rock. Because the stress variation of the coal seam roof and floor after mining are measured, in the process of model making, on the coal seam roof , and both side of the border of the goaf, two group strain sheets were set, and five group strain sheets are in the floor of the excavation area at every $20 \mathrm{~cm}$, the roof overburden rock above the backfill in the excavation area, five groups strain sheets are laid at every $20 \mathrm{~cm}$. Twenty minutes intervals during the process of mining stress data will be continuous acquisition until the end of filling mining and model being stable.

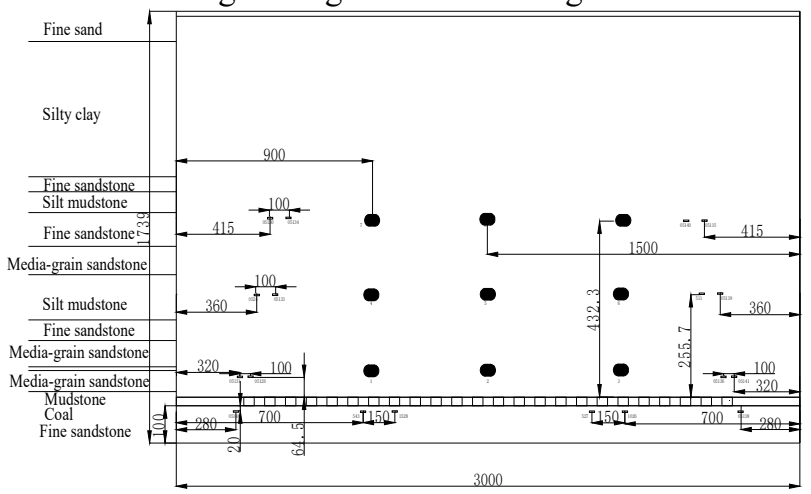

Fig.1 Arrangement of stress points

\subsection{Model materials}

According to the condition of 2307 working face of some coal mine, the raw materials for similar simulated materials are selected. Similar simulation materials are mainly composed of two components: aggregate and cementing materials. The proportion of aggregate is large, and it is the object of cementing material. Its physical and mechanical properties have an important influence on the properties of similar materials. In this experiment, fine sand is selected for the aggregate, and lime and gypsum are used for cementing material. The filling body is a special foam material in proportion to the strength of coal body, which has certain scalability and is similar to the compression performance of the actual filling material.

\subsection{Simulation scheme setting}

Actual mining of coal seam thickness is $3.7 \mathrm{~m}$, according to the conditions of the coal seam thickness and similarity ratio, considering the influence of mining 
thickness and roof subsidence, the first simulation scheme is $95 \%$ of filling rate, the thickness of the module is $3.5 \mathrm{~cm}$, width is $5 \mathrm{~cm}$, the second simulation scheme is $70 \%$ of filling rate, the thickness of the module is $2.6 \mathrm{~cm}$, and the third way filling rate is $50 \%$, the thickness of the module is $1.8 \mathrm{~cm}$. The filling material is made of materials with certain strength and compression characteristics. Modules being $1 \mathrm{~cm}, 1.8 \mathrm{~cm}$ and $0.7 \mathrm{~cm}$ are respectively made.The mining and filling method is $10 \mathrm{~m}$ excavation and $5 \mathrm{~m}$ filling, $30 \mathrm{~cm}$ coal pillar on both sides of the model is used as the boundary condition.

\section{Experimental result analysis}

\subsection{Overburden failure characteristics analysis}

When the filling rate is $95 \%$, due to less space between filling body and roof, packing material can effectively support the overlying strata in the goaf, roof only occur tiny fractures in low layers, immediate roof does not break, the whole strata in the support of filling block is intact, as shown in figure 2.

When filling rate is $70 \%$, the subsidence space of immediate roof is expanded, and the fracture scope of rock stratum extend obviously, along with the mining working face advancing, fissure gradually goes forward, behind working face the fissure gradually closed, the roof separation crack develops upward. When the working face is pushed up to $135 \mathrm{~m}$, the crack length and width reach the maximum. In the end mining-induced fractures are uneven distribution in the area of about $95.4 \mathrm{~m}$ above the coal seam, There are obvious oblique longitudinal fractures in the lower strata and penetrating fractures in the immediate roof, but the continuity is basically maintained, effectively prevent the further subsidence and displacement of the overlying strata (figure 3 ).

When filling rate is $50 \%$, the equivalent mining height is about $1.85 \mathrm{~m}$, the scope、length and width of overlying rock fractures are further extended during the process of filling mining. The roof will occur fault and collapsed about $8.5 \mathrm{~m}$ above the coal seam. Vertical cracks appear layer by layer near stopping line and cutting hole, and rock crack angle is $55^{\circ}$ or so, the fracture height reached the roof above $138.5 \mathrm{~m}$, near the cutting hole the longitudinal fracture crack is up to the roof strata about $47.5 \mathrm{~m}$. The rock strata movement and failure characteristics of the equivalent height which is like it being in a single mining are presented.

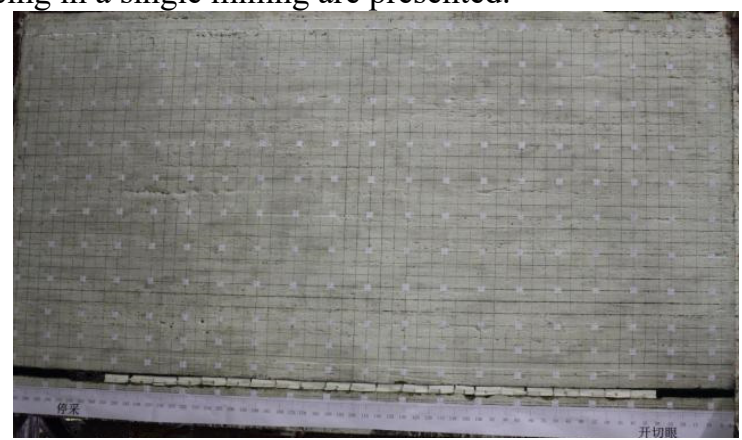

Fig.2 Deformation and failure characteristics of overlying strata with $95 \%$ filling rate

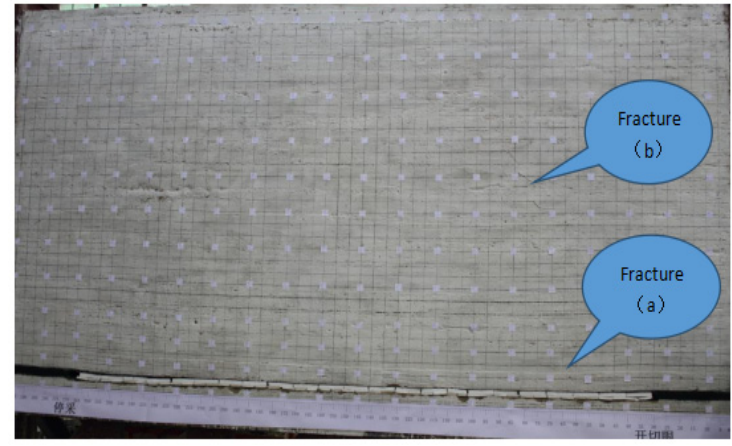

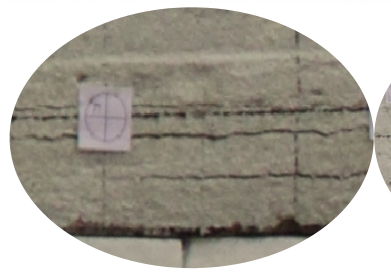

(a)

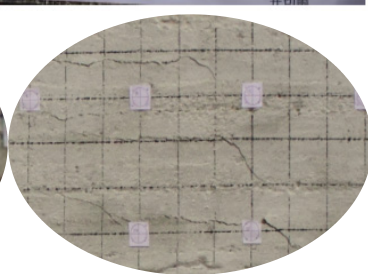

(b) (a) immediate roof delamination fracture

(b) overburden strata fracture

Fig.3 Deformation and failure characteristics of overlying strata with $70 \%$ filling rate

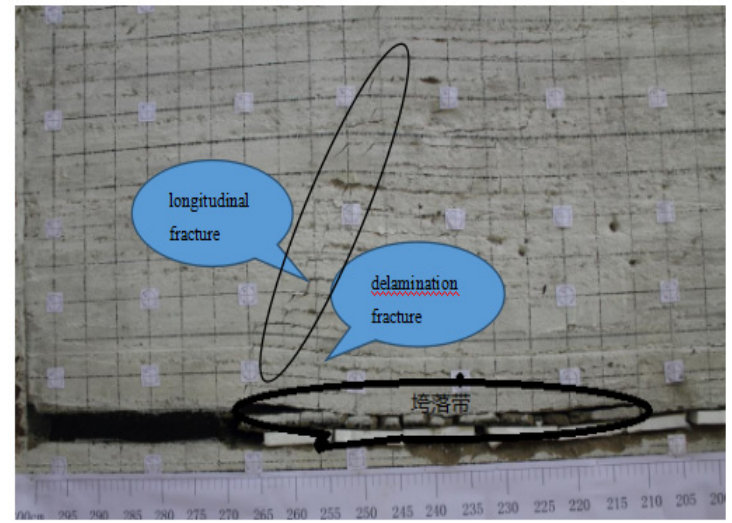

Fig.4 Deformation and failure characteristics of overlying strata with $50 \%$ filling rate

\subsection{Overburden rock stress evolution law}

Packing material to replace the coal seam, on the one hand, filling body's strength can resist stress changes which come from the original rock destruction, on the other hand, packing material can absorb part of the concentrated stress through its compressing deformation. In the process of working face advance, the measuring point stress at $150 \mathrm{~m}$ reflects the evolution rule of roof stress . Working face advance from the cutting hole, the measuring data is the original rock stress, with working face advancing to the measuring point, its stress increases gradually, when the working face advancing to the point below, the stress reduced rapidly, after the working face in the surrounding rock stress gradually restored, the stress gradually stabilized, and close to the original rock stress, as shown in figure 5 . 


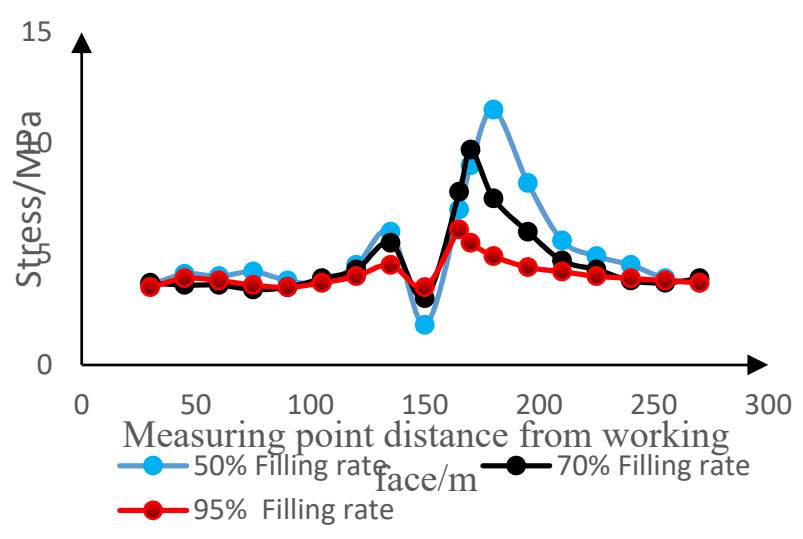

Fig. 5 Curve of stress variation

With the different filling rate the effect distance and the maximum stress of strata are difference in the working face advancing. When the filling rate is $50 \%$
$95 \%$, the coal wall stress peak ahead of the working face is $3.1 \gamma \mathrm{H} \sim 1.6 \gamma \mathrm{H}$, the advance impact distance is $15 \sim 30$ $\mathrm{m}$. with the filling rate increasing, the range of stress disturbance and the distance between the working face and pressure peak of the coal wall are reduced. Table 2 shows the stress distribution characteristics of different filling rates. As shown in fig. $6 \sim$ fig. 7 , there is a power function between the influence distance of mining and the filling rate(Formula 1), the degree of concentrated stress decreases linearly with the increase of filling rate(Formula 2). The stress distribution characteristics show that increasing the filling rate can effectively increase the surrounding rock stress and reduce the stress concentration degree and range.

Table 2 Stress distribution characteristics of different filling rates

\begin{tabular}{cccc}
\hline Filling rate & $\begin{array}{c}\text { Maximum } \\
\text { stress(MPa) }\end{array}$ & $\begin{array}{c}\text { advance impact } \\
\text { distance }(\mathrm{m})\end{array}$ & $\begin{array}{c}\text { Stress concentration } \\
\text { factor }\end{array}$ \\
\hline $50 \%$ & 11.5 & 30 & 3.1 \\
$70 \%$ & 9.7 & 21 & 2.4 \\
$95 \%$ & 6.1 & 15 & 1.6 \\
\hline
\end{tabular}

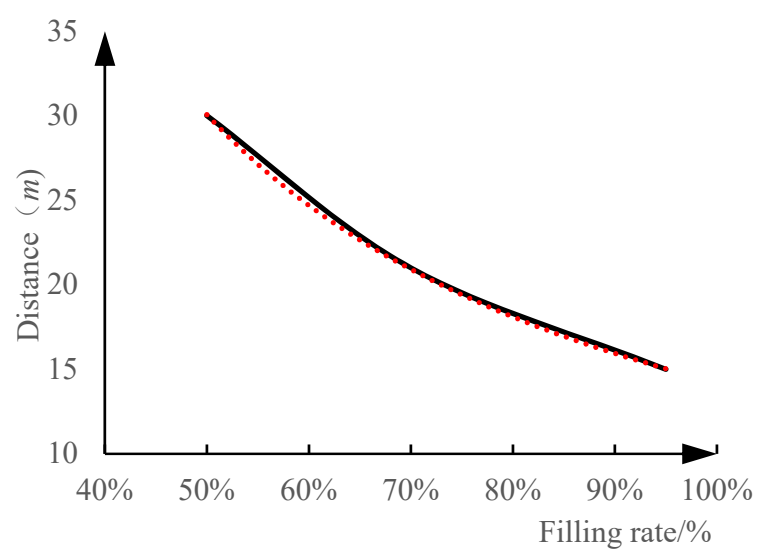

Fig. 6 Relationship between filling rate and influencing distance

$y=14.225 x^{-1.08}, \mathrm{R}^{2}=0.9999$

$y=-12.098+17.77, \mathrm{R}^{2}=0.9842$

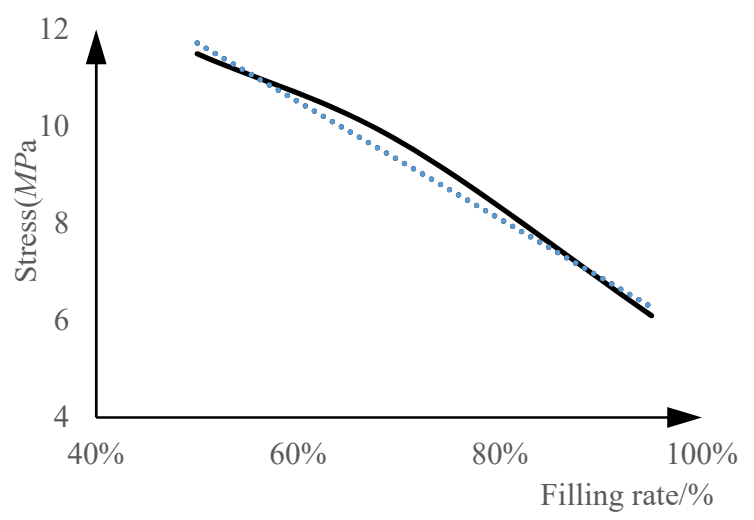

Fig. 7 Relationship between filling rate and stress peak

\subsection{Overburden displacement analysis}

When the filling rate is different, the displacement of each strata is a great difference.The displacement of measured line in overburden rock was taken for study, as shown in fig. $8 \sim$ fig. 10 . From the strata displacement distribution analysis, along the strike of rock displacement with partition characteristics, in the left side of the border to cutting hole $0 \sim 30 \mathrm{~m}$ segment and in the right boundary to the stopping line $270 \sim 300 \mathrm{~m}$ are the boundary pillar area, the area call the slow subsidence area, $30 \sim 80 \mathrm{~m}$ segment is sinking speed zone, $80 \sim 225 \mathrm{~m}$ segment is stabilize the subsidence area, $225 \sim 270 \mathrm{~m}$ segment is sinking deceleration zone.

In the slow subsidence area of the cutting hole or stopping line,there is a significant difference in the displacement of measuring points of each layer,and the vertical displacement of overburden rock to the surface increases successively, which is more and more obvious with the filling rate increasing. Cutting hole and stopping line are the key positions to the strata movement,which is transformation point of the strata movement accelerating. In the acceleration area that is from the cutting hole rock stratum displacement increase rapidly,and in the reduction of subsidence area before stopping line the rock stratum displacement in falling rapidly, The inclination deformation of rock stratum and surface are maximum in the acceleration zone and deceleration zone. In the middle region of the model, the displacements of stable subsidence area are disparity greatly due to the difference filling rate. In this region, the subsidence displacement of the roof is relatively flat and its shape is "pot bottom".

When filling rate is $95 \%$, the roof maximum vertical displacement is $420 \mathrm{~mm}$, and the value of rock stratum that measurement line being $15 \mathrm{~m}$ away from coal seam is $417 \mathrm{~mm}$, the value of surface is $415 \mathrm{~mm}$. The vertical displacements of roof, middle rock and surface are continuous and similar,it is basically consistent and no 
significant mutation.It shows the complex rock is relatively intact, roof without fault, the rock layers being relative accordance, overburden rock does not appear large vertical displacement and separating layer.

When filling rate is $70 \%$, the displacements of measurement lines of roof, middle strata distance from coal seam being $15 \mathrm{~m}$ and $32.5 \mathrm{~m}$, and the surface were analyzed, the roof maximum vertical displacement is $1222 \mathrm{~mm}, 15 \mathrm{~m}$ away from coal seam in strata the maximal displacement is $1015 \mathrm{~mm}$, from $32.5 \mathrm{~m}$ away from coal seam maximum vertical displacement is $933 \mathrm{~mm}$, the surface maximum vertical displacement is $880 \mathrm{~mm}$. the direct roof rock displacement is bigger and the surface displacement is smaller, so the direct roof subsidence is obvious, and overburden rock fracture reach in the higher, the displacement of different height line have a little distinguish.

When the filling rate is $50 \%$, the displacements of measurement lines of roof, middle strata distance from coal seam being $15 \mathrm{~m} 、 32.5 \mathrm{~m}$ and $62.5 \mathrm{~m}$ and the surface, a total of five line were analyzed. and the displacements of roof , middle and the surface were difference larger,in the roof maximum vertical displacement is $2114 \mathrm{~mm}$, at the strata $15 \mathrm{~m}$ away from coal seam the maximal displacement is $1901 \mathrm{~mm}$, at $32.5 \mathrm{~m}$ of coal seam maximum vertical displacement is $1685 \mathrm{~mm}$, being 62.5 $\mathrm{m}$ from coal seam maximum vertical displacement is $1471 \mathrm{~mm}$, on the surface maximum vertical displacement is $1256 \mathrm{~mm}$.The vertical displacements of every lines have markedly difference, in the model at the same distance from the cutting hole, the different height measuring point vertical displacements distribution are relatively uniform, shows that when the filling rate is $50 \%$,the space of the mined-out area enlarge, the roof is severe damaged and higher, the destructing fracture have different width in all the rock strata, so that the vertical displacement takes place obvious difference.

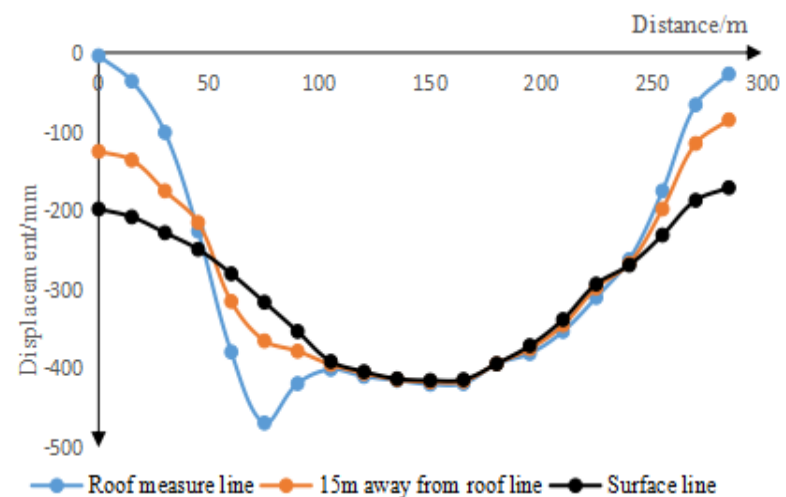

Fig.8 Subsidence curve of overlying strata with $95 \%$ filling rate

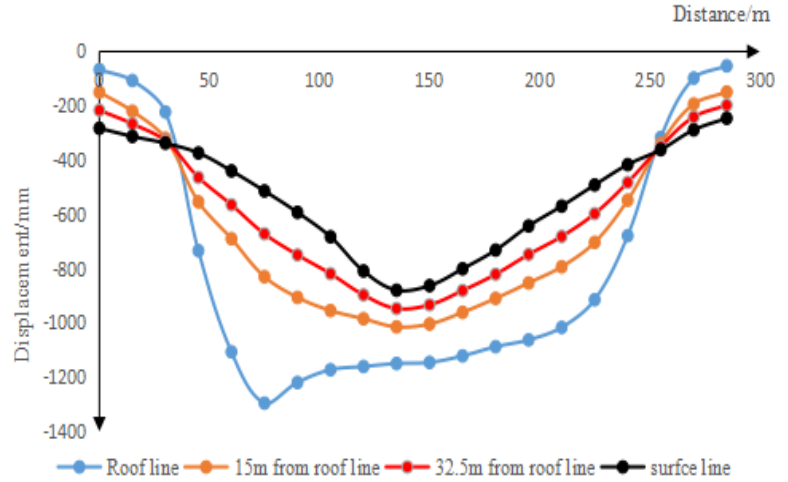

Fig.9 Subsidence curve of overlying strata with $70 \%$ filling rate

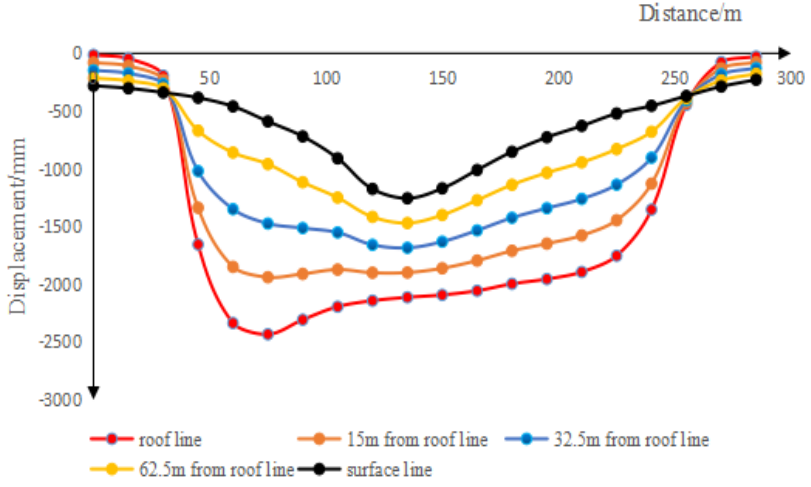

Fig.10Subsidence curve of overlying strata with $50 \%$ filling rate

\section{Conclusions}

(1) The physical test model reasonably reflects the geological and mining conditions of the selected working face, simulates the filling process of different filling rate , and obtains the failure range of the overburden, the law of the displacement of the rock layer and the characteristics of the stress evolution.

(2) With the filling rate increases, the equivalent mining height decreases, the displacement space of the roof reduces, and the overburden rock recede damage. When filling rate is low, strata deformation acute damage, fracture distribution scope expand, the longitudinal crack and transverse abscission appear, immediate roof collapse,It produces equivalent mining height being broken characteristics of roof rock liking by caving method, while filling rate is higher, the cracks appeared only in low strata and strata overall relatively complete.

(3) During the filling mining progress, the coal pillar before and after the working face will have stress concentration. When the filling rate is high, the stress concentration coefficient is small and the advance distance is short. When the filling rate is low, the stress concentration coefficient is large and the advance distance is long. There is a power function between the mining influence distance and the filling rate, the concentrated stress decreases linearly with the increase of filling rate.

(4) The displacement distribution law is consistent with the failure form of overburden rock, and when the filling rate is low, not only the displacement of roof is larger, but also the vertical displacement of each rock stratum is differentiated significantly. Filling rate is high, 
strata displacement main occurs near the immediate roof, the strata displacement curves in the stable subsidence area are almost together, the rock presents the overall bending deformation, from the roof to the surface layers are whole movement characteristics.

(5) Through physical simulation calculation and analysis with different filling rate, the filling rate is an important factor to control the surface deformation, different filling rate affected the strata rock mechanics properties of "three zones", the results of the study are of great significance to guide practice in filling mining.

\section{References}

1. Yan Shao hong,Zhang Hua xing .Status of filling mining technology in Coal Mines of China [J]. Coal mining technology,2008,82(03):1-3+10.

2. Miao Xiexing,Qian Minggao.Research on green mining of coal resources in China:current status and future prospects[J].Journal of Mining \& Safety Engineering,2009,26(1):1-14.

3. Hu bing nan. Backfill Mining Technology and Development tendency in China Coal mine [J]. Coal science and technology,2012,456(11):1-5+18.

4. GongPeilin, $\mathrm{Hu}$ yaoqing,Zhao yangsheng,etal.Three-dimensional simulation study on law of deformation and breakage of floor on mining above aquifer[J]. Chinese of Journal of Rock Mechanics Engineering,2005,24(23):4396-4402.

5. Yang ke, Xie guangxiang, Changjucai. Experimental investigation into mechanical characteristics of surrounding rock with different mining thickness $[\mathrm{J}]$. Journal of coal science,2009,34(11):1446-1450.

6. $\mathrm{Xu}$ mengtang,Zhang dongsheng,Ma liqiang,etal.Roof control technology for longwall filling mining of superhigh-water material[J].Journal of china coal society,2014,39(03):410-416.

7. Liu jiangong, zhao jiafei, li mengmeng, etal.Continuous curved beam formation and strata control theory in coal backfill mining [J]. Journal of china coal society,2016,41(02):383-391.

8. Sun qiang, zhang jixiong, Yin wei, etal.Study of stability of surrounding rock and characteristic of overburden strata movement with longwall roadway backfill coal mining [J]. Journal of china coal society,2017,42(02):404-412.

9. Yu weijian, feng tao, wang weijun, etal. Cooperation support system in mining with filling and mechanical behavior [J]Journal of rock mechanics engineering,2012,262(S1):2803-2813.

10. Changqing liang, Zhou huaqiang, Bai jianbiao, etal. Stability study and practice of overlying strata with paste backfilling [J]. Journal of mining and safety engineering,2011,97(02):279-282.

11. Chen shaojie, guo weijia, zhou hui, etal.Structure model and movement law of overburden during strip pillar mining backfill with cream-body [J]. Journal of china coal society,2011,202(07):1081-1086.

12. Wang Jiachen, Yang Shengli,Yang Baogui,et al.Simulation experiment of overlying strata movement features[J].Journal of China Coal Society, 2012,37(8):1 256-1 262. 